\title{
Perancangan Chatbot Menggunakan Dialogflow Natural Language Processing (Studi Kasus: Sistem Pemesanan pada Coffee Shop)
}

\author{
Albert Yakobus Chandra ${ }^{1}$, Didik Kurniawan ${ }^{2}$, Rahmat Musa ${ }^{2}$ \\ ${ }^{1}$ Program Studi Sistem Informasi, Universitas Mercu Buana Yogyakarta, Yogyakarta, Indonesia \\ ${ }^{2}$ Program Studi Teknik Informatika, Universitas Mercu Buana Yogyakarta, Yogyakarta, Indonesia \\ Email: ${ }^{1}$ albert.ch@mercubuana-yogya.ac.id, ${ }^{2}$ didikboy96@gmail.com, ${ }^{3}$ kangmusa518@gmail.com
}

\begin{abstract}
Abstrak-Beberapa kasus yang sering dialami pada suatu instansi tertentu seperti UMKM adalah seringnya seorang staff/karyawan dalam memberikan pelayanan informasi dan transaksi yang dilakukan secara manual kepada pelanggan yang berkaitan dengan kegiatan usaha tersebut. Siklus ini selalu berulang dari pelanggan yang satu dengan yang lain. Dampaknya apabila terjadi kondisi dimana terdapat antrian yang cukup ramai maka beban kerja staff/karyawan akan semakin tinggi dan resiko terjadi kesalahan pada transaksi pun akan meningkat. Perkembangan teknologi informasi dalam bidang artificial intelligence dalam era industri 4.0 saat ini berkembang dengan sangat pesat. Salah satunya adalah Machine Learning - Natural Language Processing (NLP) yang merupakan salah satu ilmu yang berfokus pada bagaimana komputer dapat memahami dan mengerti bahasa manusia dan dapat memberikan respon. Oleh karena itu pada penelitian ini akan dibangun system chatbot yang dapat melayani pelanggan dalam memberikan informasi dan melakukan transaksi secara otomatis. Chatbot ini dibangun dengan memanfaatkan tools Dialogflow dari Google. Chatbot yang dibangun dapat berkomunikasi, menerima dan menyimpan transaksi dengan pelanggan. Hasil yang diharapkan adalah system chatbot ini dapat menjadi alternatif yang dapat diimplementasikan pada berbagai usaha untuk memberikan pelayanan yang lebih baik bagi pelanggan.
\end{abstract}

Kata Kunci: Chatbot, Dialogflow, Machine Learning, Natural Language Processing, Artificial Intelligence

\begin{abstract}
Some cases that are often experienced at a particular institution such as Micro Enterprise are often a staff / employee in providing information services and transactions that are carried out manually to customers related to these business activities. This cycle always repeats from one customer to another. The impact if there are conditions where the queue of customer that is quite crowded than the workload of staff/employees will be higher and the risk of error in transactions will be high too. The development of information technology in artificial intelligence on 4.0 industry era is moving forward. One of them is Machine Learning - Natural Language Processing (NLP) which is one of the sciences that focuses on how computers can understand the human language and response to it. Therefor in this research a chatbot system will be builtin providing information and conducting transaction with the customers. This chatbot will be develop using the Dialogflow tools provided by Google. This Chatbot that was build expected to be an alternative that can be implemented in various bussines to provide better service for customers.
\end{abstract}

Keywords: Chatbot, Dialogflow, Machine Learning, Natural Language Processing, Artificial Intelligence

\section{PENDAHULUAN}

Artikel Perubahan dunia kini tengah memasuki era revolusi industri 4.0 atau revolusi industri dunia keempat dimana teknologi informasi telah menjadi basis dalam kehidupan manusia. Segala hal menjadi tanpa batas (borderless) dengan penggunaan daya komputasi dan data yang tidak terbatas (unlimited), karena dipengaruhi oleh perkembangan internet dan teknologi digital yang masif sebagai tulang punggung pergerakan dan konektivitas manusia dan mesin. Era ini juga akan mendisrupsi berbagai aktivitas manusia dalam berbagai bidang, seperti Pendidikan, budaya, pemerintahan maupun bisnis [1].

Perkembangan teknologi saat ini telah memberikan pengaruh yang sangat besar bagi dunia teknologi informasi dan telekomunikasi. Munculnya beragam aplikasi memberikan pilihan dalam peningkatan kinerja suatu perusahaan atau UMKM, baik yang berbasis desktop, mobile maupun web. Peningkatan keakurasian serta efisiensi informasi dalam pemanfaatan teknologi komputer tentu lebih menjanjikan daripada penggunaan tenaga manusia secara manual. Hal ini karena sifat teknologi komputer yang otomatis dalam pekerjaannya.

Artificial Intelligence sudah dikenal mulai tahun 1950an dicetuskan oleh Alan Turing. Alan Turing menciptkana suatu tes yang dinamakan Turing Test. Turing Test merupakan test kecerdasan dalam mesin komputer yang menunjukkan bahwa seorang manusia tidak mampu membedakan jawaban mesin dan manusia lainnya saat diberikan pertanyaan yang sama sehingga kecerdasannya dapat diukur setara dengan manusia [2].

Coffee shop merupakan tempat ramai yang sering dikunjungi oleh setiap orang yang ingin menghabiskan waktunya untuk bersantai dan berbincang-bincang maupun menyelesaikan tugas pribadi, dimana pengunjung dapat memesan minuman dan makanan sesuai yang diinginkan. Pelanggan yang datang harus terlebih dahulu memesan lewat kasir untuk mendapatkan pesanan yang diinginkan, dari situlah terjadi proses transaksi dimana staff/pelayan mencatat pesanan yang diajukan oleh pelanggan, setelah proses transaksi selesai barulah pelanggan mencari tempat duduk yang di inginkan. Dalam melayani pelanggan terkadang customer service harus melayani para pelanggan secara manual satu persatu. Keterbatasan tenaga manusia tentu akan menghambat efektifitas berjalannya bisnis. Bila terjadi proses antrian yang ramai staff/karyawan biasanya kewalahan dalam melayani pelanggan karena banyaknya pesanan yang diterima sehingga membuat kesalahan yang tidak diinginkan. Misalnya kesalahan dalam pencatatan pesanan, kesalahan penentuan meja pelanggan dan sebagainya, belum lagi jika terjadi situasi dimana pelanggan bingung dan lama dalam pemilihan pesanan, ini tentu akan menimbulkan dampak berupa 
antrian yang panjang dan lama. Oleh karena itu diperlukannya suatu sistem teknologi berbasis AI (Artificial Intelligence) yang dapat melayani pelanggan tanpa harus membuang waktu dan tenaga.

Pemilihan system chatbot sebagai prasarana informasi dan transaksi pada sebuah industry UMKM akan lebih memudahkan dalam manajemen pelayanannya, karena sifat otomatis chatbot dalam penyampaian informasi dan transaksi dari mesin kepada pelanggan secara realtime.

Dalam pengembangan system chatbot sendiri, pengembang akan melatih computer dalam memahami bahasa manusia sekaligus memberikan respon yang sesuai berdasarkan pertanyaan seputar infomasi dan transaksi yang di sampaikan oleh pelanggan. Pengembang dalam system chatbot ini tidak hanya sebatas pada pelayanan informasi dan transaksi saja, tetapi juga memberikan keunikan pada pesan-pesan yang akan di tampilkan pada system chatbot ini. Hal ini bertujuan agar pelanggan terhibur dan tidak merasa jenuh dengan bahasa-bahasa yang ditampilkan oleh system chatbot ini.

\section{METODE PENELITIAN}

\subsection{Pendekatan Penelitian}

Menurut Sugiyono, metode penelitian adalah cara ilmiah yang digunakan peneliti untuk mendapatkan data dengan tujuan dan kegunaan tertentu [3]. Dalam penelitian ini, metode yang digunakan adalah dengan metode pendekatan deskriptif kualitatif. Penelitian kualitatif adalah penelitian yang menggunakan latar alamiah dengan maksud untuk memahami fenomena tentang apa yang dialami oleh subjek penelitian secara holistik (utuh), dengan mendeskripsikan data dalam bentuk kata-kata dan bahasa, dan dengan memanfaatkan berbagai metode alamiah [4]. Dalam penelitian kualitatif data yang dikumpulkan bukan berupa angka-angka melainkan data tersebut berasal dari naskah wawancara, catatan lapangan, dokumen pribadi, catatan memo, gambar (foto) dan dokumen resmi lainnya [5].

\subsection{Metode Pengumpulan Data}

Metode pengumpulan data dapat diperoleh secara langsung dari contoh kasus yang diteliti. Sumber data di dalam penelitian merupakan factor yang sangat penting, karena sumber data akan menyangkut kualitas dari hasil penelitian. Oleh karenanya, sumber data menjadi bahan pertimbangan dalam penentuan metode pengumpulan data. Sumber data terdiri dari data primer dan data sekunder [6]. Tahapan pengumpulan data yang digunakan pada penelitian ini antara lain:

1. Studi Literatur

Studi literatur dilakukan guna mendapatkan data sekunder yang merupakan sumber data secara tidak langsung yang di dapatkan oleh pengumpul data, misalnya melalui orang lain atau lewat dokumen. Sumber data sekunder digunakan untuk mendukung informasi yang didapatkan dari sumber data primer yaitu dari bahan pustaka literatur, penelitian terdahulu, buku, laporan-laporan kegiatan yang diadakan oleh perpustakaan dan lain sebagainya [7].

2. Studi Lapangan

Studi lapangan dilakukan guna mendapatkan data primer yang merupakan sumber data secara langsung yang di dapatkan oleh pengumpul data [7]. Studi ini dilakukan dengan cara mengunjungi tempat yang berhubungan dengan contoh kasus yang akan diteliti. Dalam studi ini pengumpulan data yang dilakukan meliputi:

a. Wawancara

Wawancara adalah salah satu pengumpulan data yang dilakukan di lapangan, cara ini dilakukan guna mendapatkan data-data yang berkaitan dengan proses informasi dan transaksi yang terjadi di tempat pelaku usaha café. Adapun narasumber yang akan diwawancarai meliputi manajer, staff dan pelanggan.

b. Observasi

Observasi adalah pengumpulan data yang dilakukan dengan cara pengamatan secara langsung di tempat pelaku usaha café, dengan sasaran objek adalah staff/karyawan dan pelanggan.

\subsection{Chatbot}

Chatbot adalah program, perangkat lunak, yang menggunakan bahasa pemrosesan alami (Natural Language Processing) dalam sebuah pertanyaan dan sistem jawab (system QA: sistem tanya jawab) [9]. Chatbot merupakan suatu program komputer yang melakukan percakapan dengan menggunakan metode auditori atau tekstual. Umumnya program ini dibangun untuk meyakinkan atau mensimulasikan bagaimana manusia bisa berperilaku sebagai mitra percakapan. Chatbot bisa menginterprestasikan serta memberi tanggapan dengan berbagai macam input manusia, seperti yang sudah dibahas di atas bahwa sebenarnya bots tersebut bekerja dengan memindai kata kunci dalam input, setelah itu dibalas dengan kata kunci yang paling cocok atau bisa pula dengan pola kata yang paling mirip dari basis data tekstual. Jadi, jika pengguna mengirim suatu permintaan maka bots tersebut akan mengirim kembali respon secara spesifik yang berdasarkan pada query yang dikirim [10]. Chatbot bekerja dengan mengartikan pesan yang diberikan oleh pengguna, kemudian memproses maksud dari pesan tersebut, selanjutnya menentukan dan mengeksekusi apa yang perlu chatbot lakukan berdasarkan perintah dari pengguna, dan terakhir menyampaikan hasil dari eksekusi program kepada pengguna [11]. 


\subsection{Natural Language Processing}

Natural Language Processing (NLP) memungkinkan mesin ke mesin atau interaksi manusia ke mesin menggunakan bahasa alami terkait manusia [12]. Disiplin ini difokuskan pada mempelajari kemampuan komputer untuk memahami dan memproses bahasa manusia untuk selanjutnya menghasilkan tanggapan darinya. Beberapa metode adalah digunakan untuk memahami kata-kata dan niat dari pengguna yang ada berkomunikasi dalam suatu konteks: dari pencarian teks yang sederhana pola dalam pesan pengguna ke artifisial yang lebih canggih teknik kecerdasan diterapkan pada bahasa manusia [13].

\subsection{Metode Pengembangan Perangkat Lunak}

Metode yang digunakan adalah SDLC (System Development Life Cycle) dengan model pengembangan waterfall. Model Waterfall merupakan salah satu model pengembangan perangkat lunak yang ada di dalam model SDLC (Sequencial Development Life Cycle) [8]. Seperti ditujukan pada gambar berikut:

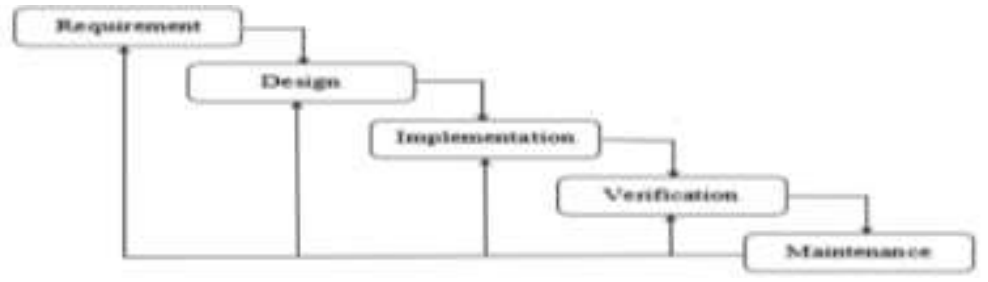

Gambar 1. Model waterfall

Adapun penjelasan mengenai tahapan-tahapan pada model waterfall adalah sebagai berikut:

1. Requirement Analysis

Tahap requirement analysis adalah tahap interaksi intensif antara analisis system chatbot dengan komunitas pemakai sistem (end-user). Pada tahap ini pengembangan sistem diperlukan komunikasi yang bertujuan untuk memahami chatbot yang diharapkan oleh end-user dan batasan dari chatbot tersebut.

2. System Design

Design system merupakan tahap lanjutan setelah analisis kebutuhan, pada siklus pengembangan sistem. Pada tahap ini dibuat suatu gambaran dan rancang bangun yang jelas dari system chatbot agar nantinya dapat dilanjutkan kedalam proses pengkodean program. Pada proses ini berfokus pada desain dari conversation flow dan flowchart.

3. Implementation

Implementation adalah tahap lanjutan setelah design system, implementation adalah tahapan dimana design system dirancang kedalam bentuk program aplikasi.

4. Verification/Testing

Di tahap ini dilakukan penggabungan unit-unit yang sudah dibuat dan dilakukan pengujian. Ini dilakukan untuk mengetahui apakah chatbot yang dibuat telah sesuai dengan desain dan fungsinya. Di tahap ini juga dilakukan pengecekan apakah masih terdapat kesalahan pada desain sistemnya.

5. Maintenance

Maintenance adalah tahap akhir dari model waterfall. Pada tahap ini program sudah dalam bentuk jadi dan siap dijalankan serta dilakukan pemeliharaan. Pemeliharaan termasuk dalam memperbaiki kesalahan yang tidak ditemukan pada langkah sebelumnya.

\subsection{Dialogflow}

Dialogflow merupakan platform untuk membuat bot, dimana platform ini mencocokan kata dari request user kemudian diolah oleh "Agent" Machine Learning lalu memberikan umpan balik kepada user dengan response dan output data dengan format JSON.

\section{HASIL DAN PEMBAHASAN}

Dialogflow menggunakan Google Machine Learning untuk mengolah request user yang masuk, Dialogflow juga mendukung 30 bahasa diantaranya, bahasa inggris, hindi, jepang, korea, indonesia, dan lainnya. Dialogflow merupakan web apps yang bisa digunakan oleh siapa saja, baik developer ataupun bukan developer sekalipun, tidak perlu coding untuk membuat aplikasi chatbot yang sederhana. Dialogflow juga menyediakan integrasi dengan code yang dibuat oleh pengguna dengan memakai layanan Cloud Functions for Firebase, Dialogflow akan mengirim HTTP Request dalam JSON kepada Cloud untuk mengintegrasikannya [14]. Berikut gambar dari alur kerja pada API Dialogflow. 


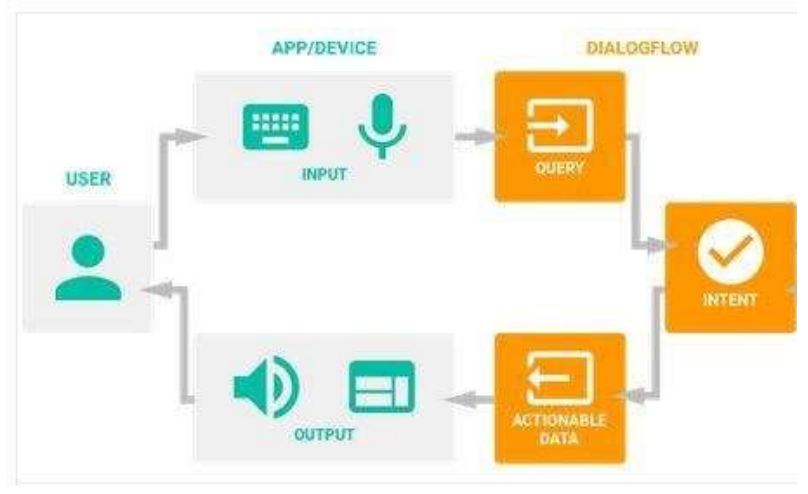

Gambar 2. Alur Kerja Dialogflow

Beberapa Fitur Dialogflow

1. Create Agent

Merupakan modul NLU (Natural Language Understanding), digunakan untuk manajemen flow conversation. Yang harus dilakukan untuk membuat agent adalah dengan masuk ke situs http://dialogflow.com, lalu pada dashboard menuju ke console (Go to Console). Setelah itu login menggunakan akun Google, lalu situs akan mengarahkan halaman untuk membuat bot kemudian akan ditujukan pada halaman console tempat konfigurasi bot $[14]$.

2. Create Intent

Intents merupakan fitur yang digunakan untuk mengenali apa yang user inginkan, dalam intents akan dibuat apa yang user katakan dan aksi apa yang seharusnya diambil. Intent memiliki beberapa komponen diantaranya adalah Training Phrases dimana tempat untuk menginputkan kata maupun kalimat yang akan dikatakan oleh user, walau tidak ada dalam list Machine Learning Model akan mendeteksi kalimat user dan mencocokan dari beberapa kalimat contoh yang telah dibuat sebelumnya, kedua Actions and Parameters ini merupakan fitur yang digunakan untuk mendefinisikan suatu kata kedalam suatu aksi yang berisi entity dan parameter value dari Actions, ketiga Response merupakan kalimat yang akan diterima oleh user berdasarkan kalimat yang diterima, dan yang terakhir Context merupakan fitur untuk menyimpan informasi dari percapakan sebelumnya untuk dilanjutkan ke dalam percakapan selanjutnya [14]. Berikut daftar intent dalam perancangan chatbot untuk kasus Coffee Shop ini:

Tabel 1. Intent

\begin{tabular}{|c|c|c|}
\hline Intent 1 & Intent 2 & Intent 3 \\
\hline \multicolumn{3}{|l|}{ Default Welcome Intent } \\
\hline \multicolumn{3}{|l|}{ Default Fallback Intent } \\
\hline \multicolumn{3}{|l|}{ Menu } \\
\hline \multirow{4}{*}{ Order_Drink } & Follow-Un Intent: Order Drink - & $\begin{array}{l}\text { Follow-Up Intent: Order_Drink_Yes } \\
\text { - Delivery }\end{array}$ \\
\hline & Yes & Follow-Up Intent: Order_Drink_Yes \\
\hline & Follow_Un Intent. Order Drink & \\
\hline & $\begin{array}{l}\text { Follow-Up Intent: Order_Drink - } \\
\text { No }\end{array}$ & \\
\hline \multirow{4}{*}{ Order_Snack } & & Follow-Up Intent: Order_Snack_Yes \\
\hline & Follow-Up Intent: Order_Snack - & - Delivery \\
\hline & & $\begin{array}{l}\text { Follow-Up Intent: Order_Snack_Yes } \\
\text { - Pick-Up }\end{array}$ \\
\hline & $\begin{array}{l}\text { Follow-Up Intent: Order_Snack - } \\
\text { No }\end{array}$ & \\
\hline
\end{tabular}

3. Create Entities

Entities merupakan fitur yang digunakan untuk mengambil parameter value dari query yang dikirim oleh user. Entities dibagi menjadi tiga yaitu, pertama System Entities merupakan entites yang dibuat langsung oleh Dialogflow seperti @sys.time, @sys.date, @sys.email, @sys.phone-number, dan masih banyak lagi, kedua. Developer Entities merupakan entities yang dibuat oleh developer sendiri, dan ketiga User Entites merupakan entities yang dibuat berdasarkan session id dari user seperti barang yang pernah dibeli user atau playlist dari user [14]. Pada perancangan chatbot ini, peneliti manambah beberapa entities untuk memenuhi parameter value tambahan yang antara lain@menu, @drink, @snack, @flavor, @milk-type, @iced, @no_meja, @topping, @ delivery_pick-up dan @ size. 
Available Online at https://ejurnal.stmik-budidarma.ac.id/index.php/mib DOI 10.30865/mib.v4i1.1505

Adanya conversational flow bertujuan agar percakapan antara chatbot dan pelanggan memiliki aliran dan aturan yang baku. Pelanggan akan bertanya mengenai sesuatu, namun sebelum keinginan pelanggan dipenuhi harus ada langkah-langkah yang harus dilalui. Berikut gambar alur kerja dari conversation flow untuk chatbot coffee shop ini.

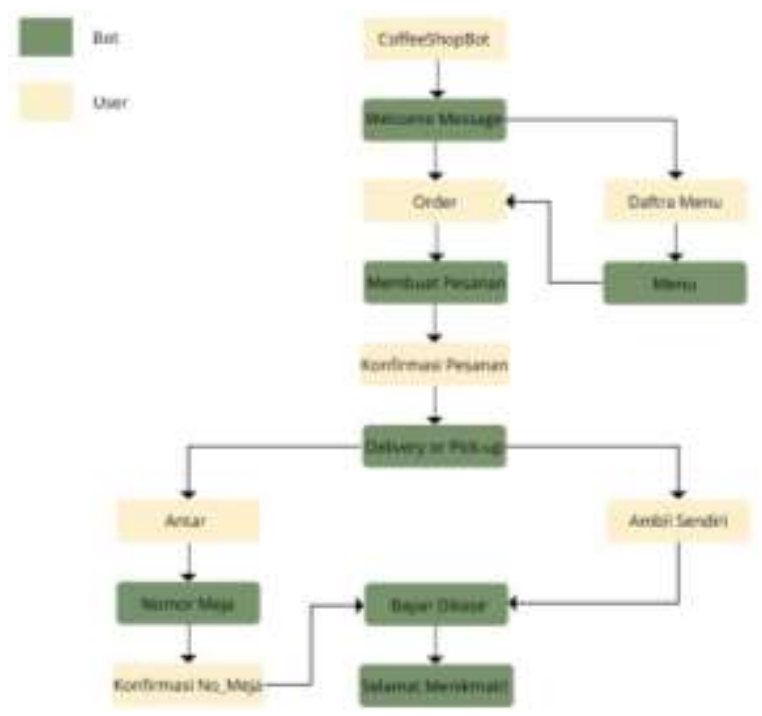

Gambar 3. Conversation Flow

System chatbot memiliki dua respon yang berbeda terkait dengan inputan user experience, antara lain:

a. Default Fallback, yaitu respon chatbot terkait pertanyaan-pertanyaan user seputar topik permasalahan.

b. Non-Default Fallback, yaitu respon chatbot terkait pertanyaan-pertanyaan user diluar topik permasalahan.

\subsection{Alur Kerja Sistem}

Flowchart system merupakan bagan yang menunjukan alur kerja atau apa yang sedang dikerjakan didalam percakapan secara keseluruhan dan menjelaskan urutan dari prosedur-prosedur yang ada dalam sistem percakapan user - bot. Adapun untuk flowchart dari sistem chatbot ini dapat dilihat pada gambar berikut:

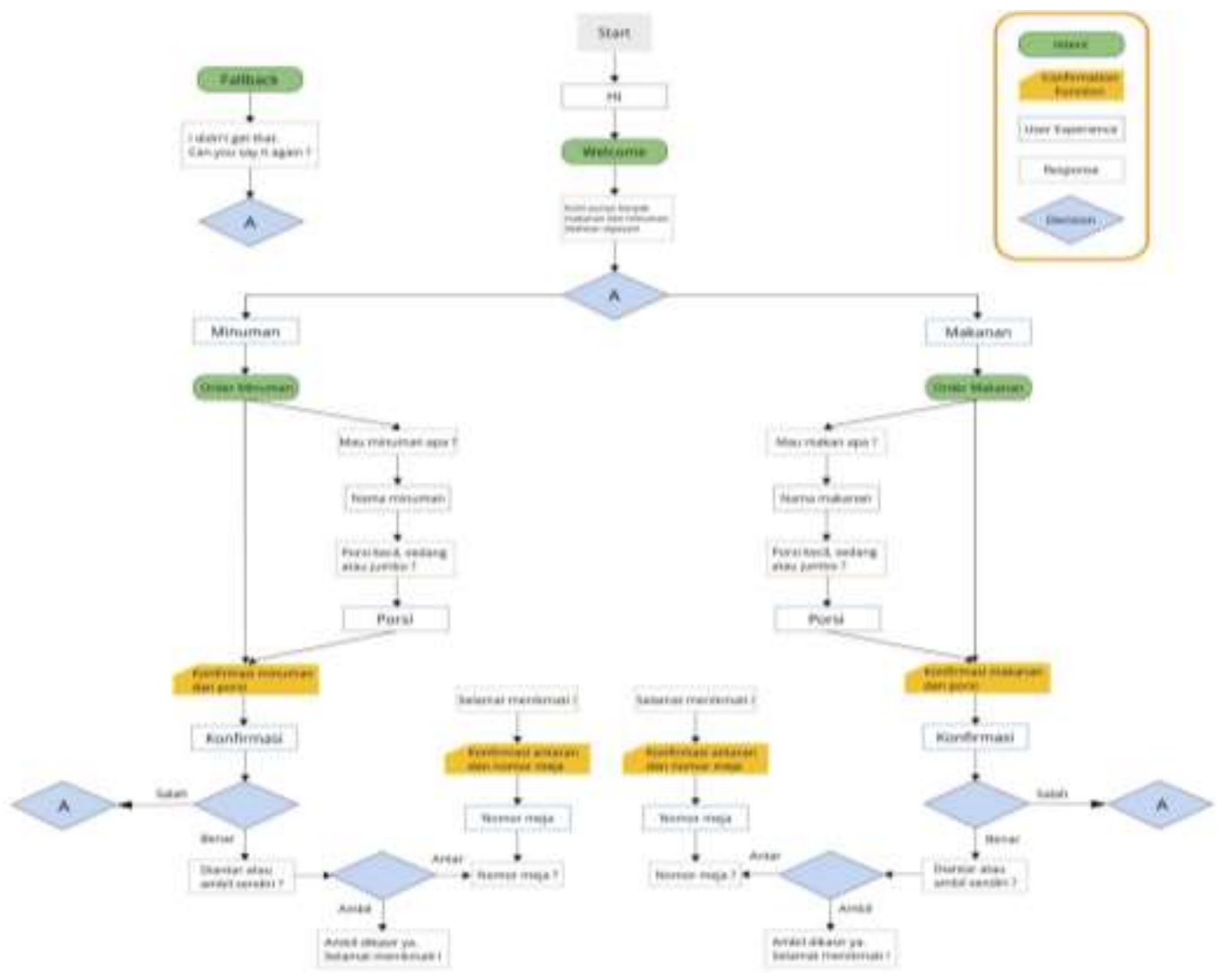

Gambar 4. Flowchart

Albert Yakobus Chandra, Copyright (c) 2020, MIB, Page 212 
JURNAL MEDIA INFORMATIKA BUDIDARMA

Volume 4, Nomor 1, Januari 2020, Page 208-215

ISSN 2614-5278 (media cetak), ISSN 2548-8368 (media online)

Available Online at https://ejurnal.stmik-budidarma.ac.id/index.php/mib DOI 10.30865/mib.v4i1.1505

\subsection{Implementasi}

\subsubsection{Default Welcome Intent}

Default welcome intent adalah proses awal dimana user pertama kali memulai chatbot atau memberikan sapaan kepada chatbot, lalu 'bot' akan memberi respon yang sesuai dengan training phrases. Misal: 'Hai' atau 'hallo'. Seperti ditujukan pada gambar berikut:

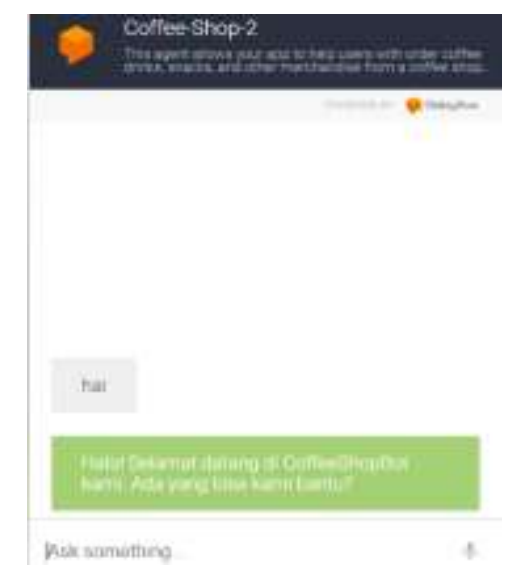

Gambar 5. Default Welcome Intent

\subsubsection{Default Fallback Intent}

Default fallback intent adalah proses dimana user memberikan respon yang tidak terdapat pada intent, lalu 'bot' akan memberi respon berupa pesan error kepada user. Misal: 'Jam berapa' atau 'bisa pesan tiket pesawat gak' Seperti ditujukan pada gambar berikut:

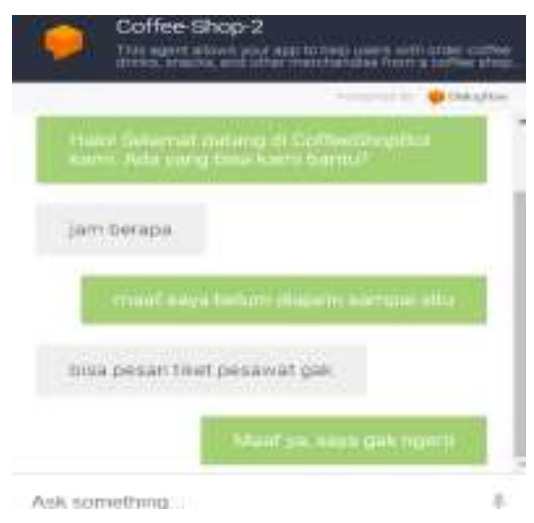

Gambar 6. Default Fallback Intent

\subsubsection{Menu}

Menu adalah proses dimana user memberikan kalimat yang berhubungan dengan konteks menu, lalu 'bot' akan memberi respon berupa daftar menu pada coffee shop. Misal: 'Ada menu apa aja' atau 'boleh liat menu'. Seperti ditujukan pada gambar berikut:

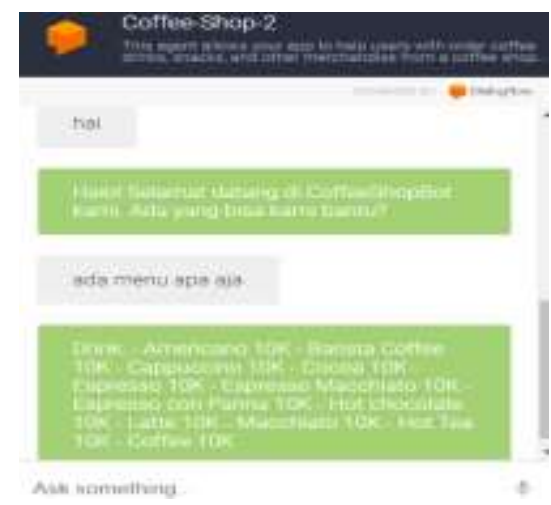

Gambar 7. Intent 'Menu' 
JURNAL MEDIA INFORMATIKA BUDIDARMA

Volume 4, Nomor 1, Januari 2020, Page 208-215

ISSN 2614-5278 (media cetak), ISSN 2548-8368 (media online)

Available Online at https://ejurnal.stmik-budidarma.ac.id/index.php/mib DOI 10.30865/mib.v4i1.1505

\subsubsection{Order Drink}

Intent Order drink adalah proses dimana user membuat pesanan minuman, lalu 'bot' akan melakukan pencatatan berdasarkan permintaan dari user. Misal: user memesan sebuah cappuccino sebanyak 3 gelas ukuran besar dengan campuran susu rendah lemak, lalu 'bot' mencatat pesanan dan memberi instruksi apakah pesanan ingin diantar atau diambil sendiri. Lebih lengkap seperti ditujukan pada gambar berikut:

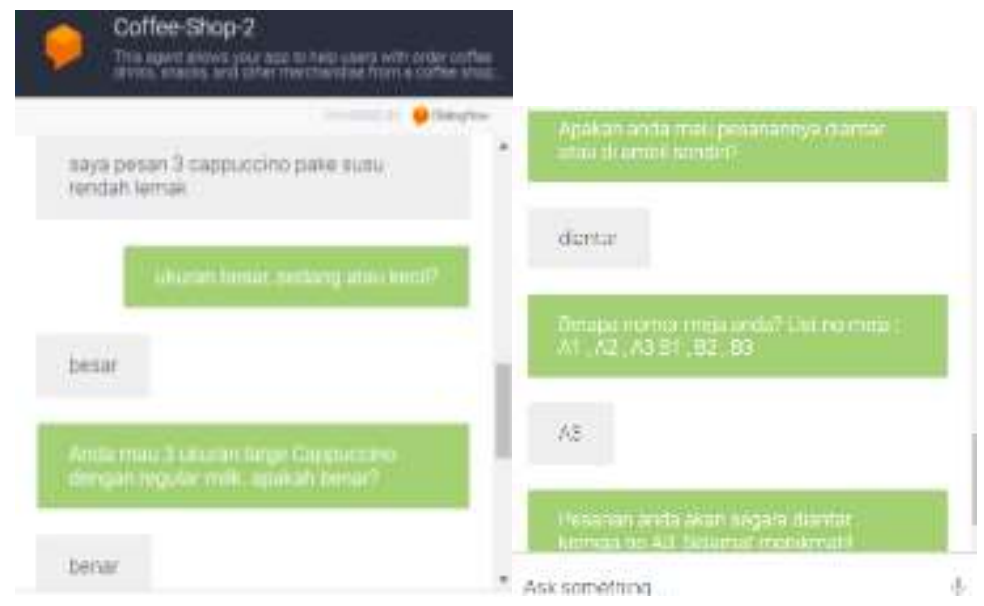

Gambar 8. Intent 'Order Drink'

\subsubsection{Order Snack}

Intent order snack adalah proses dimana user membuat pesanan makanan, lalu 'bot' akan melakukan pencatatan berdasarkan permintaan dari user. Misal: user memesan sebuah Cupcake dan strawberry sebanyak 2 buah, lalu ' $b o t$ ' mencatat pesanan dan memberi instruksi apakah pesanan ingin diantar atau diambil sendiri. Lebih lengkap seperti ditujukan pada gambar berikut:

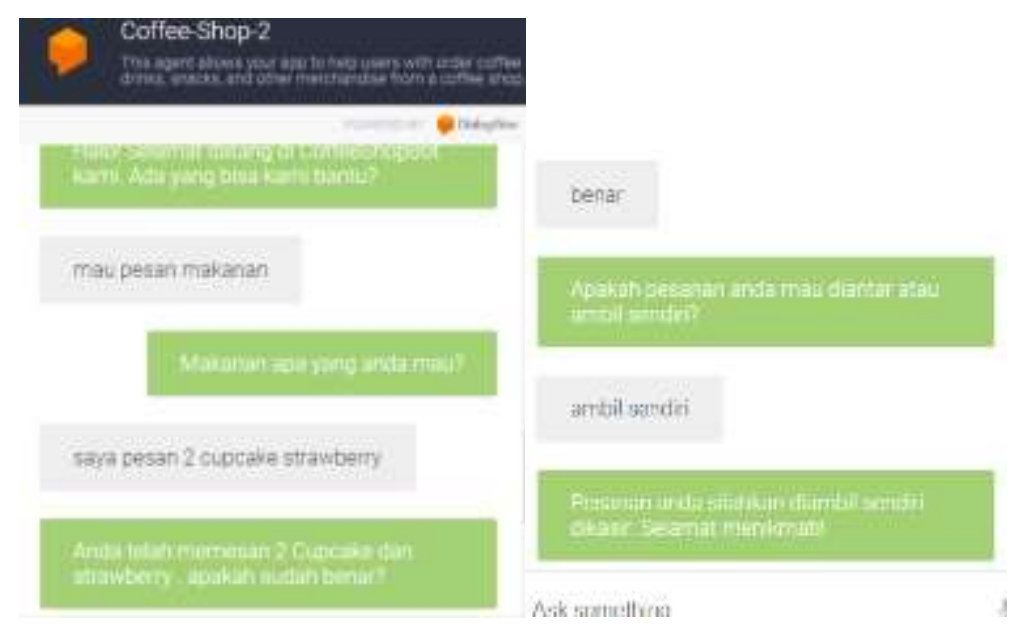

Gambar 9. Intent 'Order Snack'

\section{KESIMPULAN}

Setelah melakukan penelitian pada perancangan chatbot ini, penulis dapat menarik beberapa kesimpulan antara lain:

a. Chatbot memberikan pelayanan secara real-time.

b. Penggunaan chatbot akan optimal selama user memberikan inputan kalimat yang sesuai dengan pemetaan respon pada intent.

c. System chatbot cukup fleksibel untuk mengenali perintah-perintah baru dari user.

d. Chatbot akan otomatis memberi respon berdasarkan konteks kata yang terdapat pada entities.

e. Pada perancangan chatbot untuk kasus coffee shop ini, bot hanya dilatih untuk dapat melayani transaksi dan menampilkan pilihan menu saja. 
JURNAL MEDIA INFORMATIKA BUDIDARMA

Volume 4, Nomor 1, Januari 2020, Page 208-215

ISSN 2614-5278 (media cetak), ISSN 2548-8368 (media online)

Available Online at https://ejurnal.stmik-budidarma.ac.id/index.php/mib

DOI 10.30865/mib.v4i1.1505

\section{REFERENCES}

[1] Kemenristekdikti Republik Indonesia, "Pengembangan Iptek dan Pendidikan Tinggi di Era Revolusi Industri 4.0," RISTEKDIKTI, 2018. [Online]. Available: https://www.ristekdikti.go.id/siaran-pers/pengembangan-iptek-danpendidikan-tinggi-di-era-revolusi-industri-4-0/. [Accessed: 01-Oct-2019].

[2] D. Jean, C. Sihombing, and A. Wirapraja, "Tren Penerapan Artificial Inteligence Pada Bidang Akuntansi , Energi Terbarukan Dan Proses Industri Manufaktur ( Studi Literatur ),” vol. 15, no. 2, pp. 302-315, 2018.

[3] Sugiyono, Metode Penelitian Administrasi. Bandung: Alfabet, 2010.

[4] L. Moleong, J., Metodologi Penelitian Kualitatif. Bandung: PT Remaja Rosdakarya, 2000.

[5] H. Nabawi, Metode Penelitian Bidang Sosial. Yogyakarta: Gajah Mada Pres, 2005.

[6] W. Purhantara, Metode Penelitian Kualitatif Untuk Bisnis. Yogyakarta: Graha Ilmu, 2010.

[7] Sugiyono, Metode Penelitian Kuantitatif, Kualitatif dan R\&D. Bandung: PT Alfabet, 2016.

[8] Y. Firmansyah and U. Udi, "Penerapan Metode SDLC Waterfall Dalam Pembuatan Sistem Informasi Akademik Berbasis Web Studi Kasus Pondok Pesantren Al-Habib Sholeh Kabupaten Kubu Raya, Kalimantan Barat,” J. Teknol. dan Manaj. Inform., vol. 4, no. 1, 2017.

[9] P. Perez, F. De-La-Cruz, X. Guerron, G. Conrado, P. Quiroz-Palma, and W. Molina, "ChatPy: Conversational agent for SMEs," no. June, pp. 1-6, 2019.

[10] E. Wijaya and P. Pebriantara, "Rancangan Bangun Aplikasi Pembelajaran dengan Memanfaatkan Chatbot API Dialogflow dan Moodle Berbasis Android Pada SMA IT ALIA Tangerang,” @is Best [Accounting Inf. Syst. Inf. Technol. Bus. Enterp., vol. 3, no. 2, pp. 328-335, 2018.

[11] E. Shawar, B.A., \& Atwell, "Chatbot: are they really usefull?," LDV Forum, vol. 22, no. 1, pp. 29-49, 2007.

[12] S. Mohapatra, N. Shukla, S. Jain, and S. Chachra, "Nsmav-Bot: Intelligent Dual Language Tutor System," in Proceedings - 2018 4th International Conference on Computing, Communication Control and Automation, ICCUBEA 2018, 2019.

[13] D. Arteaga, J. Arenas, F. Paz, M. Tupia, and M. Bruzza, "Design of information system architecture for the recommendation of tourist sites in the city of Manta, Ecuador through a Chatbot," no. June, pp. 1-6, 2019.

[14] P. Ngakan, Nyoman, Pandika, "Pembahasan Dan Implementasi Dari Dialogflow." [Online]. Available: https://id.scribd.com/document/399041866/Pembahasan-Dan-Implementasi-Dari-Dialogflow. [Accessed: 10-Oct-2019]. 